\title{
UPDATE ON ALTERNATIVE OCCUPANT VOLUME TESTING
}

\author{
Michael Carolan \\ Michelle Priante Muhlanger \\ Volpe National Transportation Systems Center \\ US Department of Transportation \\ Cambridge, MA 02142
}

\begin{abstract}
This paper describes the conduct of the first of a series of quasi-static compression tests of rail passenger equipment being done to examine occupant volume strength. Specifically, this program is investigating methods of evaluating occupant volume integrity when loads are placed along the collision load path of the occupant volume. Budd Pioneer car 244 has been chosen as the test article to examine alternative occupant volume loading strategies. Since this car has been involved in several impact tests as part of a previous research program, it is important to verify the structural integrity of the vehicle before conducting an alternative loading test. Although the vehicle has been modified with crash energy management crush zones at both ends, the occupant volume between the body bolsters is unmodified from the original structure. The 800,000-pound compressive strength test will be used to ensure the structural integrity of the car is intact.

Before the conduct of this test, repairs were made to the crush zone. These repairs included replacement of trigger elements in the form of shear bolts and shear rivets. Additionally, energy absorbing elements were removed from the pushback coupler and primary energy absorbers because they would not contribute to the load path of this test. Steel blocks were added to the sliding sill element, enabling it to contact the fixed sill and enhancing the load-bearing capacity of the sliding-fixed sill connection.

Preliminary results of this test include an overall description of the test procedures, discussion of permanent deformation observed during the test, and presentation of finite-element simulation results. Detailed analysis of test results, including strain gage data, is ongoing. The test results are being compared with the finite-element model results in support of the next tests planned for this series. The next two tests will evaluate the carbody when it is loaded along its
\end{abstract}

collision load path to establish the elastic limit and crippling strength.

\section{INTRODUCTION}

This test is part of a series of tests being performed under the Federal Railroad Administration (FRA) Equipment Safety Research Program to evaluate the occupant volume integrity of passenger equipment [1]. The goal of this research program is to develop an alternative method of loading passenger equipment that places the load or loads on the structure along the load path experienced by collision loads. The series of tests will evaluate the occupant volume integrity of a car loaded along its collision load path. Two critical loads which will be examined are the elastic limit of the occupant volume and the crippling load.

As part of a previous FRA research program, several conventionally designed passenger railcars were retrofitted with crash energy management (CEM) features and dynamically impact tested [2]. These cars were originally built to withstand 800,000 pounds (lb) placed along the line of draft without undergoing permanent deformation. Since their construction, this 800,000-lb requirement has been expanded to a regulation (49 CFR 238.203) that applies to main-line passenger equipment [3].

These CEM cars feature a conventional load path for service loads and an alternative load path for collision loads. After inspecting the CEM cars available, the most suitable candidate was determined to be Budd Pioneer 244. This car, with CEM modifications, is shown in Figure 1.

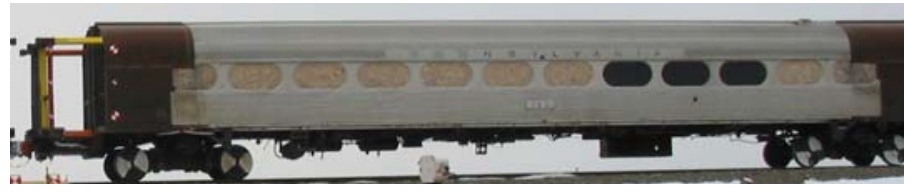

Figure 1 - Budd Pioneer 244 with CEM

This material is declared a work of the U.S. Government and is not subject to copyright protection in the United States. Approved for public release. Distribution is unlimited. 


\section{PLANNED TESTS}

A series of three tests is planned for the Budd Pioneer car. Because this car has been involved in previous dynamic impact testing, it is important to verify the structural integrity of the car. Accordingly, the first test will be an 800,000-lb buff strength test. This test will serve as a demonstration that the Pioneer Car is still structurally stable in anticipation of the elevated loads to be applied during the second and third tests. For this program's purposes, localized permanent deformation may be allowable under the $800,000 \mathrm{lb}$ load, provided the car exhibits global stability.

The next two tests will move the load to a location along the collision load path. Because this is a CEM car, the loads in tests 2 and 3 will be placed at the energy absorber support structure at the ends of the occupant volume. Test 2 is designed to be a test of the elastic limit of the occupant volume and test 3 is designed to be a test of the crippling strength of the occupant volume.

\section{0,000-Pound Buff Test}

Presently, all new passenger equipment to be operated on the general railroad system is required to comply with 49 CFR 238.203, which states that all passenger equipment must be able to sustain an 800,000-lb compressive load on the line of draft without permanent deformation. This requirement is also present in APTA SS-C\&S-034-99 [4]. This American Public Transportation Association (APTA) standard also contains details on procedures for performing a compressive strength test.

\section{TEST SPECIMEN}

Prior to this test, Budd Pioneer car 244 had been involved in five high-energy impact tests. These tests included the single- car test of conventional equipment [5], an end frame test of 1990's design equipment [6], the single-car test of CEM equipment [7], the two-car test of CEM equipment [8], and the train-to-train test of CEM equipment [9]. In the most recent test, the CEM end structure absorbed a significant amount of collision energy through controlled deformation. This particular CEM system requires certain components to be repaired or replaced before the $800,000 \mathrm{lb}$ load can be applied along the line of draft. Since the $800,000-\mathrm{lb}$ test is primarily a test of occupant volume integrity, energy-absorbing components within the CEM system will not be replaced for this test.

Figure 2 is a schematic figure of the CEM system on the Pioneer car in its undeformed state. During a collision, loads travel through the pushback coupler and its energy absorber to load a set of shear bolts between the fixed and sliding sills at the floor level and into a set of shear rivets at the roof level. The fixed sill is integrated into the underframe of the car, transmitting loads into the body bolster and center sill of the car. For this quasi-static test, the coupler and all energyabsorbing elements can be removed. However, the end frame, sliding sill, and roof absorber tubes must still be attached to the floor and the roof of the car to ensure a complete structure.

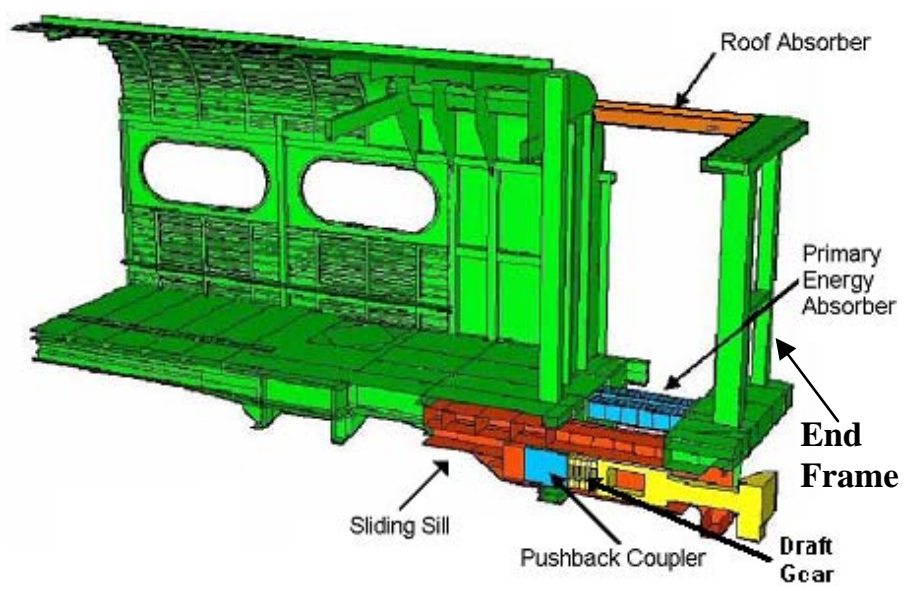

Figure 2 - Schematic View of CEM System

At each end of the car, the fixed sill and sliding sill are connected to each other by 12 bolts. As a trigger to the CEM system, these bolts are designed to fail at a prescribed load. The bolt pattern is shown below in Figure 3 for one side of one fixed sill. The replacement bolts used in the repair of the sliding sill are 1-inch (in) A490 bolts. These bolts have an approximate shear load of $80,000 \mathrm{lb}$. This gives a shear strength of approximately $960,000 \mathrm{lb}$ to the connection between fixed and sliding sills at each end of the car.

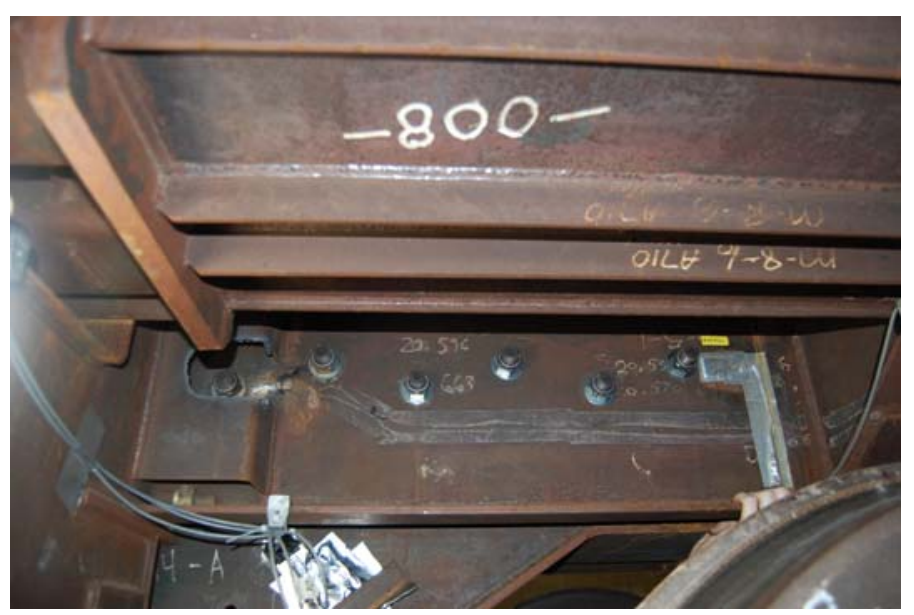

Figure 3 - Shear Bolt Pattern on Fixed/Sliding Sill Connection

At the roof level of the car, the end frame is connected to the roof structure via the roof absorber tubes. Each assembly consists of two telescoping tubes fixed to one another by a series of 1/4-inch Huck BOM fasteners. Each end of the car has two roof tubes, and each roof tube has 16 Huck fasteners. This gives a total of 32 fasteners at each car end. On the basis of the manufacturer literature, this fastener has a minimum shear load 
of 5,100 lb per rivet [10]. This gives an estimated roof load of $163,000 \mathrm{lb}$ to shear the rivets at each end of the car.

For the compressive strength test, the load of $800,000 \mathrm{lb}$ is to be placed at the buff lugs, within the draft sill. This places the load approximately 9.9 in below the centerline of the shear bolts. The centerline of the shear bolts is approximately 85.6 in below the centerline of the Huck rivet arrangement. This crosssection of the car is shown below, in Figure 4.

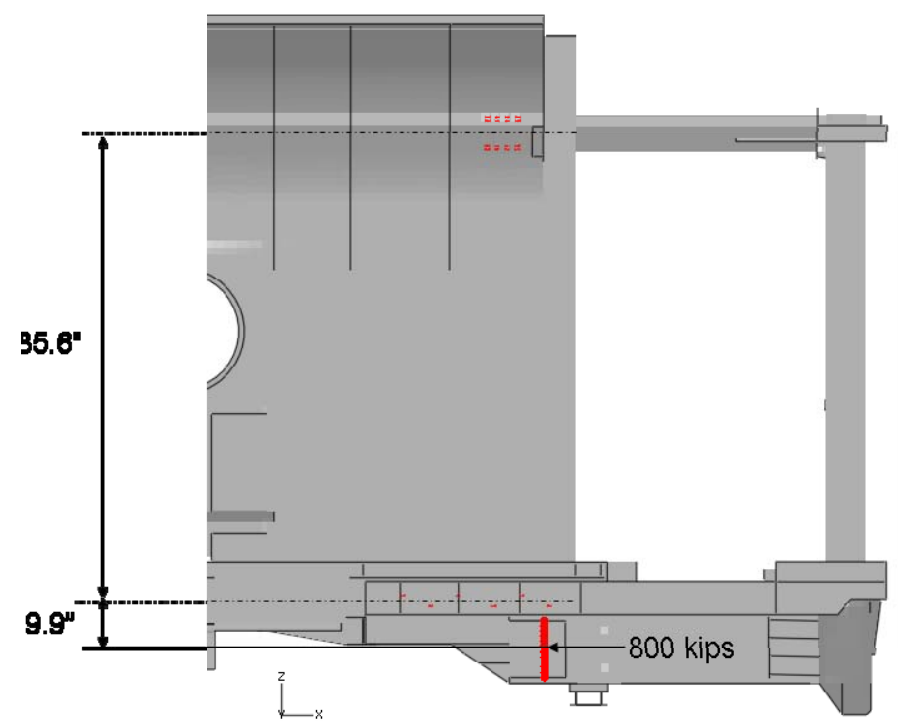

Figure 4 - Static Load Diagram

Because of the moments generated by the 800,000-lb load, the end frame will tend to pull out of the roof tube. This causes a tensile load in the shear rivets. Accordingly, the shear bolts at the fixed-sliding sill connection will experience a compressive load magnitude of greater than $800,000 \mathrm{lb}$. On the basis of the geometry of the Pioneer car, the roof experiences a tensile load of approximately $92,500 \mathrm{lb}$ and the floor compressive load is approximately 892,500 $\mathrm{lb}$.

Because the rivets at the roof have an estimated shear force of $163,000 \mathrm{lb}, 92,500 \mathrm{lb}$ is a reasonable load. However, the estimated shear load for the shear bolts on the fixed-sliding sill connection is $960,000 \mathrm{lb}$. Because this test is meant to evaluate the integrity of the occupant volume, it is undesirable to trigger any CEM components during this test. With an estimated compressive load of 892,500 lb transmitted through the shear bolts additional strength is needed in the connection between the fixed and sliding sills to increase the margin above estimated trigger load.

The most straightforward candidates for increasing the load capacity of the fixed-sliding sill connection are increasing the number of bolts used or increasing the strength of the current bolts. Because of the geometry of the sill assembly, it is not possible to drill additional holes in the fixed sill. This precludes the use of additional bolts, as well as expanding the size of the existing bolt holes. Because the A490 bolts that were previously used in this connection are of very high quality, it is not possible to increase the strength of the connection by installing higher quality bolts.

Another solution is to slightly alter the load path between the sliding sill and fixed sill, providing some relief to the amount of load traveling through the bolts. After reviewing various arrangements of increasing the load path between the fixed and sliding sills, the final configuration of interference blocks was chosen. This pattern features a steel block welded across the top of the sliding sill and two vertical blocks welded to the sides of the sliding sill. When the shear bolts are loaded, the interference blocks come into contact with the outboard cross-member of the underframe. This allows the load to be shared between the shear bolts and interference blocks. The blocks can be seen in Figure 5.

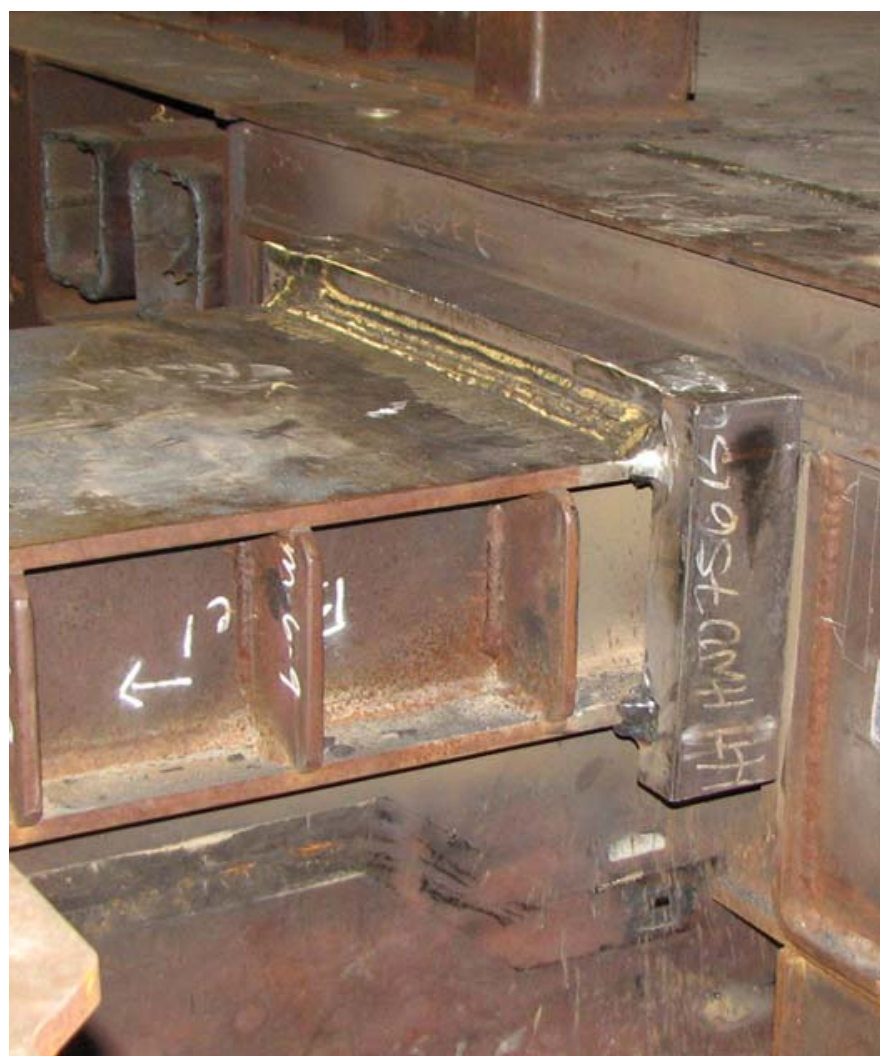

Figure 5 - B-end Interference Blocks

\section{PRETEST ANALYSES}

A detailed finite-element model has been used in developing predictions for the carbody behavior in this test. The details of this FE model are discussed in a previous paper by Carolan and Muhlanger [1].

The model used in this work features a few minor differences from the FE model discussed previously. Previously, all end frame and CEM system components were removed from the vehicle body. During the development of the testing plan, it was necessary to include the end frame, sliding 
sill, and roof tubes to facilitate loading along the line of draft. These structures have been added to the model.

Additionally, as part of the repair work performed in preparing Pioneer 244 for this test, the strength of the shear bolts and rivets making up the trigger mechanisms for the energy absorbers was investigated. These trigger elements are represented by nonlinear springs in this FE model. The FE model was also updated to include interference blocks on the sliding sill.

The commercial FE software Abaqus/CAE was used to modify the existing model [11]. The analyses that were performed were quasi-static and executed in Abaqus/Explicit. Loading was implemented by placing a pressure on the structure within the sliding sill of the car. This pressure was gradually increased with time such that the total force increased to $800,000 \mathrm{lb}$. The loaded area is shown in Figure 6.

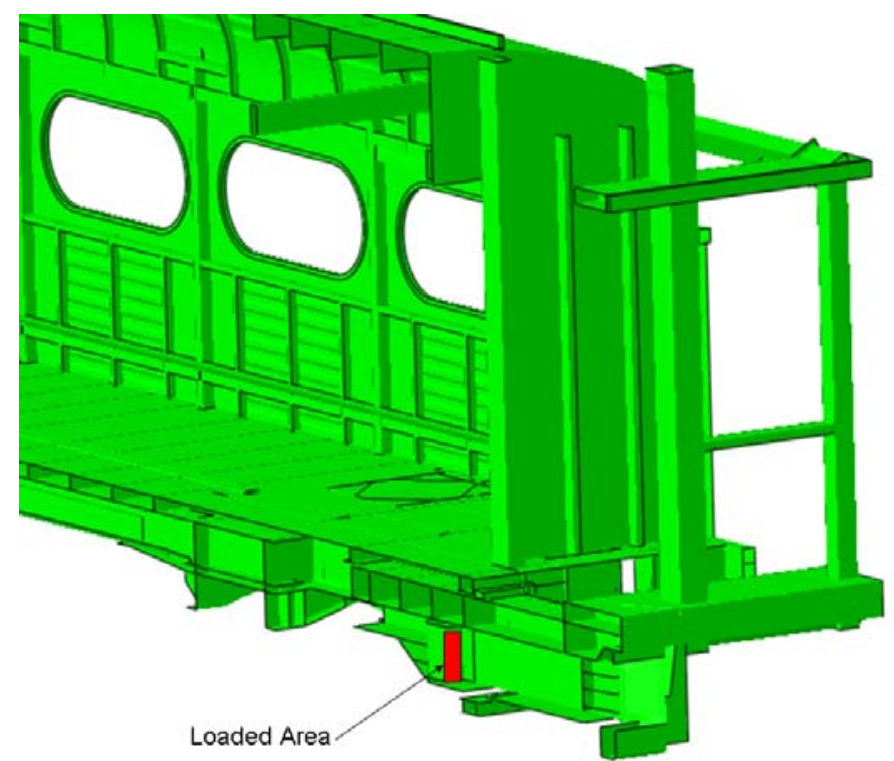

Figure 6 - Loaded Area on Sliding Sill

Force-displacement data were obtained during the simulated loading. Displacement data were recorded at the nodes making up the loaded area, whereas reaction force data were obtained at the midplane of symmetry. The applied force was calculated based on the applied pressure as a function of time. For quasi-static simulation, it is expected that the reaction forces at the front and rear of the car should be the same. The load-displacement characteristic obtained by the pretest FE analysis is shown in Figure 7.

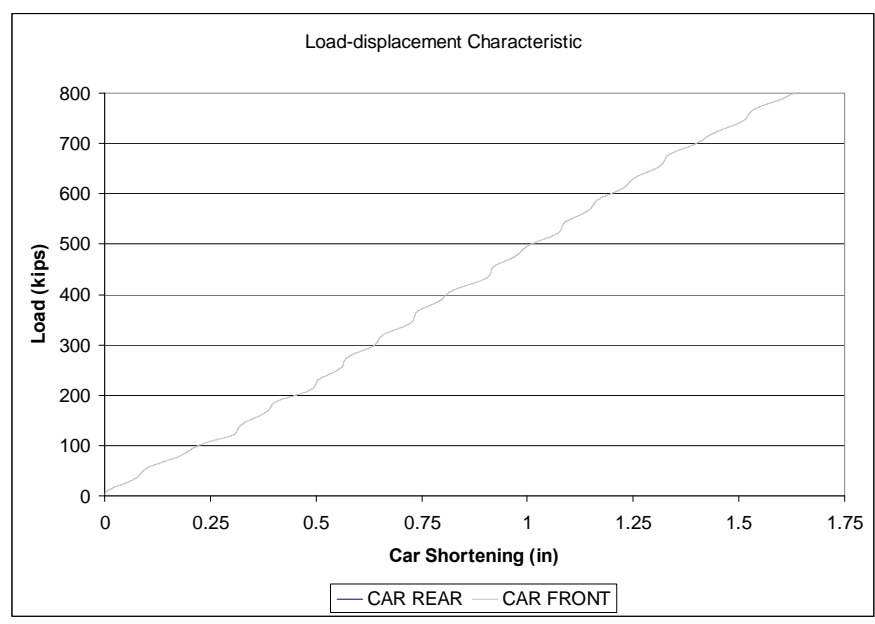

Figure 7 - Pretest FE Load-Displacement Prediction

On the basis of the pretest $\mathrm{FE}$ analyses, the overall decrease in carbody length is estimated at approximately 1.6 in when a load of $800,000 \mathrm{lb}$ is applied. In addition to this longitudinal shortening of the car, the analysis is predicting a deformation mode where the center of the car lifts upward relative to the end of the car. At 800,000 lb, the maximum uplift of the center sill is predicted to be approximately $2 \mathrm{in}$. Additionally, the two ends of the car are expected to shift vertically downward toward the ground. The deformed mode shape is shown in Figure 8, with the vertical scale of the image exaggerated by a factor of 10 for emphasis and a dashed line indicating the nominal starting level of the underframe.
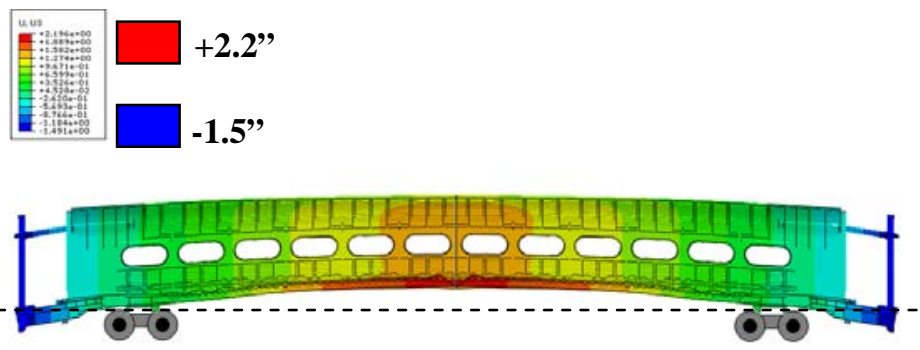

Figure 8 - Predicted Vertical Deflection (exaggerated 10x)

In addition to providing an estimated load-displacement behavior for the Budd Pioneer car, the pretest FE analysis was used to assist in placing instrumentation on the car. The FE analysis indicated potential areas of high strain where instrumentation placement would be critical. Figure 9 shows a contour plot of von Mises stress in the carbody under the 800,000-lb load. 


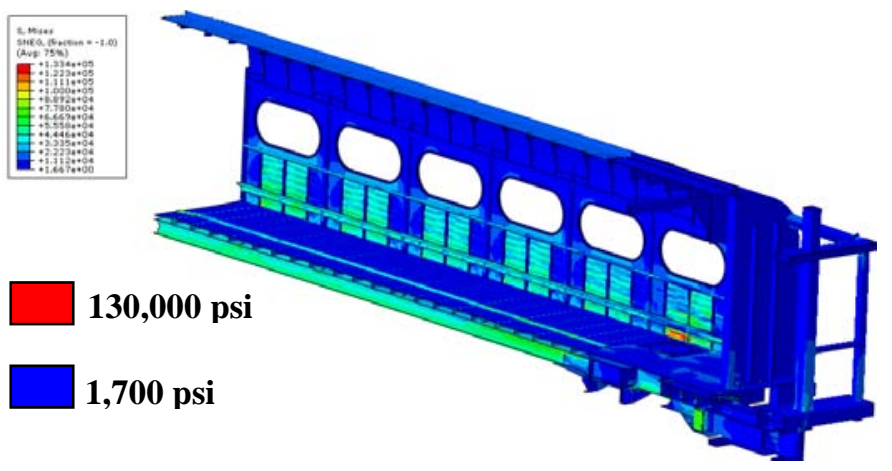

Figure 9 - Contour Plot of von Mises Stress, $\mathbf{8 0 0 , 0 0 0 ~ l b ~}$

\section{Load}

As seen in the previous figure, the model is predicting an increase of stress in the sidewall at the location of the body bolster. In addition to featuring the body bolster in the underframe, the side sill undergoes a change in cross-section in this area. In response to this prediction of high stress, strain gages were placed accordingly on the structure.

\section{TEST SETUP}

The carbody remained on its trucks during this test. The trucks provide vertical support for the carbody but do not prevent any longitudinal motion. The airbag suspension of the car was not inflated, resulting in a hard contact between the underside of the body bolster and the truck bolster.

Lateral support to the vehicle was provided through the trucks. The trucks were sitting on level, tangent track within the testing fixture. Lateral loads from the body of the car were transmitted into the trucks, through the wheel flanges, and into the rails themselves.

Longitudinal restraint is provided through the test frame. The frame consists of two $\mathrm{W}$-sections running the length of the car. At the A-end, a crosshead with hydraulic ram is fixed to ground. At the B-end of the car, a crosshead is attached between the two parallel beams. This crosshead has a block attached to it, which contacts the buff stops within the B-end sliding sill of the car.

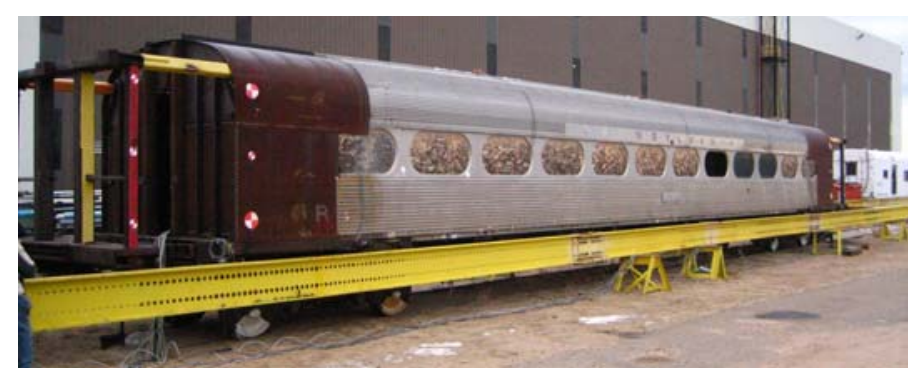

Figure 10 - Budd Pioneer Car in Test Frame
The 800,000-lb test is designed to be a quasi-static test of the occupant volume strength of the car. During the test, load is applied to the buff stops at the A-end of the car by a hydraulic ram. The ram was displacement controlled with a target load rate of less than 1 in per minute (min). In accordance with APTA SS-C\&S-034-99 rev 2, the load magnitude was increased in a number of steps. The load was held at each target value for at least 1 min before being decreased to allow for safe inspection of the vehicle structure. The target load versus time diagram is shown schematically in Figure 11.

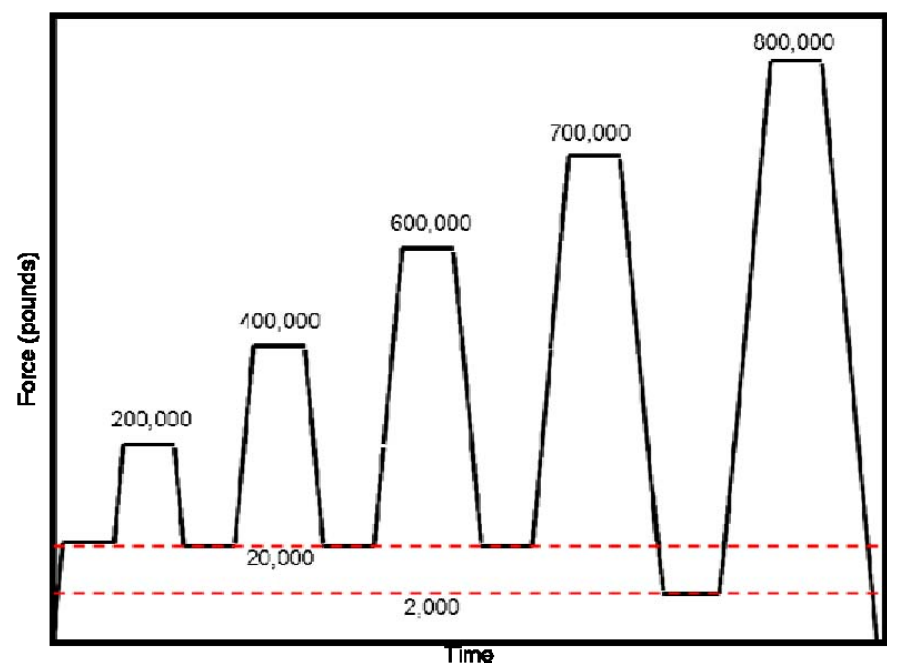

Figure 11 - Target Force-Time History

Once the carbody had been loaded to 700,000 lb, the load was decreased to a value no greater than 2,000 lb, in accordance with APTA procedures. After the target load of $800,000 \mathrm{lb}$ had been reached, the load was completely removed from the carbody. At that point, residual deformation of the unloaded carbody could be measured.

\section{INSTRUMENTATION}

Instrumentation was placed on the carbody to record global structural response to the applied load as well as strain behavior in selected areas of the structure. The global behavior of greatest interest is the force-displacement characteristic. The applied force was measured by a 1,000,000-lb capacity load cell placed between the hydraulic ram and the buff stops on the live end of the car. Displacement was recorded as total decrease in car length. This was measured by string potentiometers placed at both ends of the car, as shown in Figure 12. The difference between these two measurements provides overall change in length of the car. 


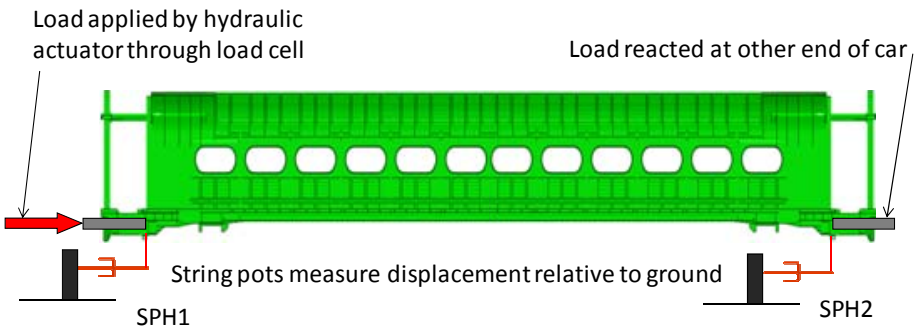

Figure 12 - Longitudinal String Potentiometers

Another key global output for the carbody response is the bending mode of the structure. This value was measured by recording the vertical deflection of the underframe with respect to the ground at different cross-sections along the length of the car. A series of string potentiometers were attached between the underside of the car and the ground, as shown in Figure 13. This figure shows one-half the length of the car; a similar string potentiometer arrangement was used on the other half of the carbody for a total of seven vertically-mounted string potentiometers.

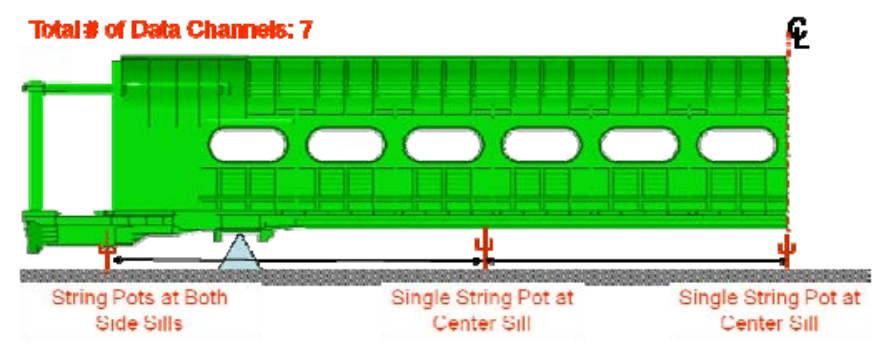

Figure 13 - Vertical String Potentiometers

In addition to the global behavior of the car, strains at specific cross-sections of the occupant volume were recorded. Uniaxial strain gages were placed on the center sill, side sills, belt rails, roof rails, and purlins of the car. These members are shown schematically in Figure 14. This figure also indicates the location of the strain gage on each cross-section with a rectangle. Strain results at these members give an overall indication of the state of stress within the occupant volume at each cross-section of the car to feature instrumentation.

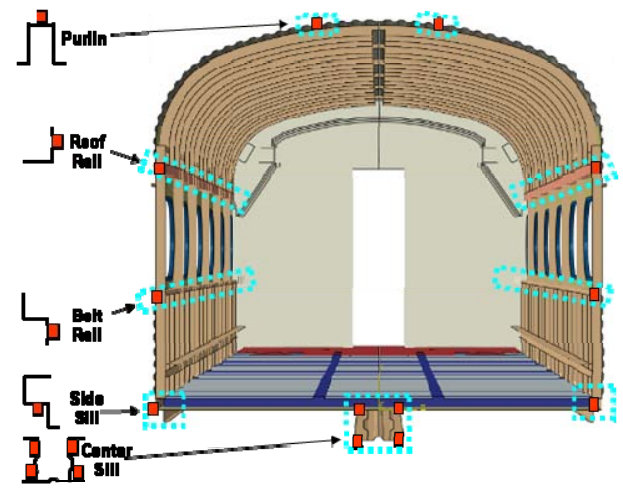

Figure 14 - Cross-Section Showing Longitudinal Members
Originally, the Pioneer carbody was symmetric on the left and right sides. It was decided that instrumenting both the left and right sides of the car would provide necessary information in case of local failure. Additionally, comparing the left and right side strains at a corresponding location builds a level of redundancy into the test.

Strain gages were placed on the occupant volume at six different cross-sections of the car so that the state of stress along the length of each member could be evaluated. These locations are shown in Figure 15. At cross-section 6, instrumentation was placed only at the belt rail and side sill. Pretest FE analysis indicated a likely high stress in the sidewall of the car in this area, warranting additional instrumentation.

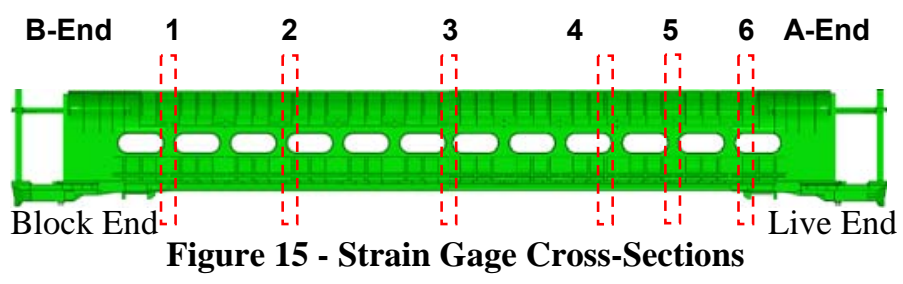

In addition to longitudinal uniaxial strain gages, three-axis strain rosettes were placed at locations on the fixed and sliding sills. These locations were expected to have high levels of strain based upon pretest FE analysis predictions. A total of eight rosettes were used on the car, one each at the left and right fixed and sliding sills on both ends of the car. The rosette placement is shown schematically in Figure 16 for one end of the car. This image shows a one-quarter symmetric view of the car taken from the FE model.

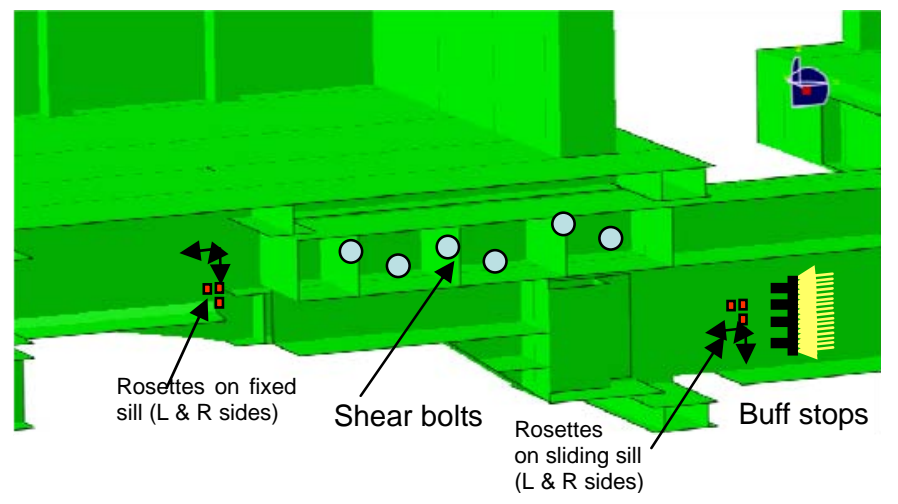

Figure 16 - Strain Rosette Locations

\section{PRELIMINARY TEST RESULTS}

Globally, the car behaved as predicted by the pretest FE analysis. At a load of $800,000 \mathrm{lb}$, the carbody shortened by approximately $2 \mathrm{in}$, while the pretest analysis estimated a shortening of $1.6 \mathrm{in}$. The 800,000-lb test load-displacement characteristics are shown in Figure 17 for the load and unload cycle. 


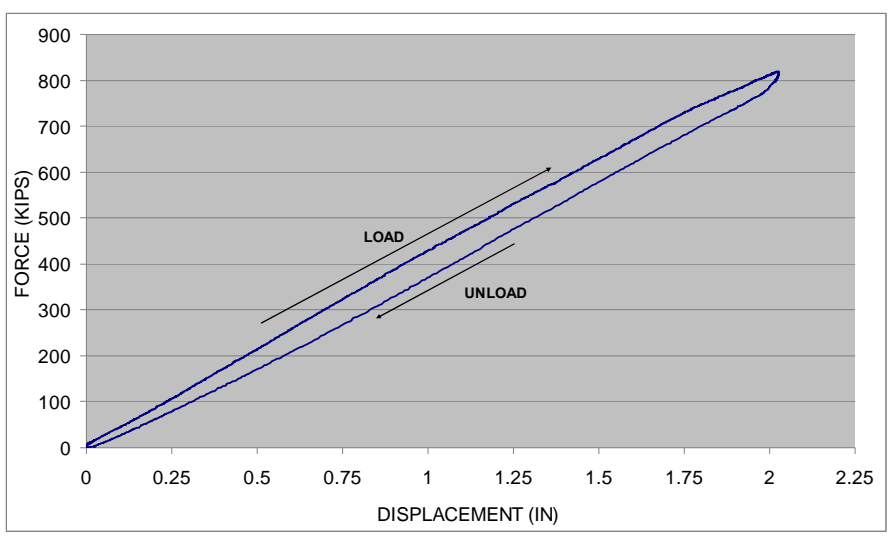

Figure 17 - Test Data, 800,000-lb Load Cycle

The top portion of this characteristic is the loading of the car and the lower portion of the characteristic is the unloading. The slope remained approximately linear until about 700,000 lb. From 700,000 to 800,000 lb, the slope softens slightly. An unexpected result of this test is the unloading characteristic of the car. For an elastic beam, the unloading characteristic is expected to overlay the loading characteristic. Also, the displacement measurement returns to zero at the end of the test, which is indicative of an elastic beam. Further analysis of the force-displacement data is required to better understand the car's behavior.

The longitudinal deformation was measured at the ends of the car, between the car and the ground. The difference between these two measurements is the shortening of the car. A more detailed look at the displacement measure will likely result in adjustments to the test data, as the horizontally mounted displacement transducers likely recorded some data on vertical and/or lateral deflection of the car.

\section{Vertical Deflection Mode}

During the test, the vertically mounted string potentiometers were observed to be measuring deflection in both the vertical and longitudinal directions because of longitudinal motion of the car at the points of attachment. Additionally, lateral motion of the carbody is likely to have occurred at higher load magnitudes. Although the shortening of the car was initially assumed to be an insignificant source of error, analysis has been conducted to resolve each string potentiometer's data into longitudinal and vertical components. Figure 18 shows one vertical string potentiometer while the carbody is loaded. The dashed line was added to indicate the vertical condition.

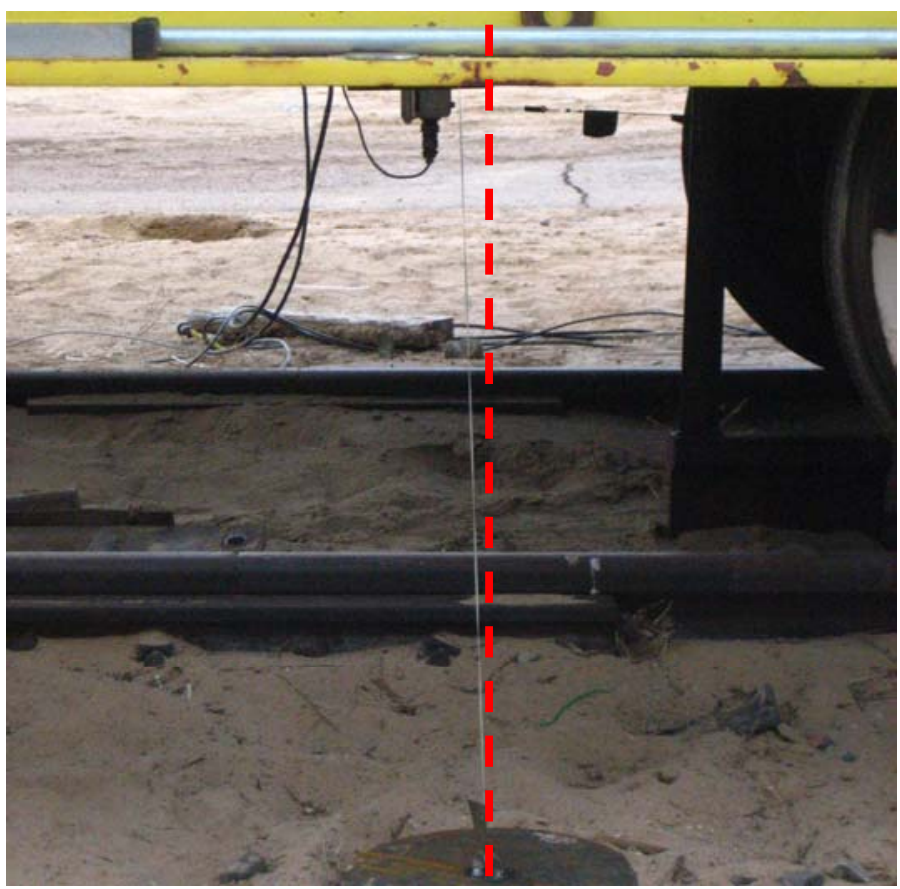

Figure 18 - String Potentiometer Showing Offset

A key measure in observing the mode of deformation during the test is the vertical displacements of the carbody along its length. Figure 19 shows the vertical displacement measurement along the length of the car, recorded during the $800,000-l b$ load cycle. The horizontal axis has its origin at the vertical string potentiometer at the blocked end of the car. As predicted in the pretest model, the ends of the car slightly dip downward. The center of the car progressively rises during the test.

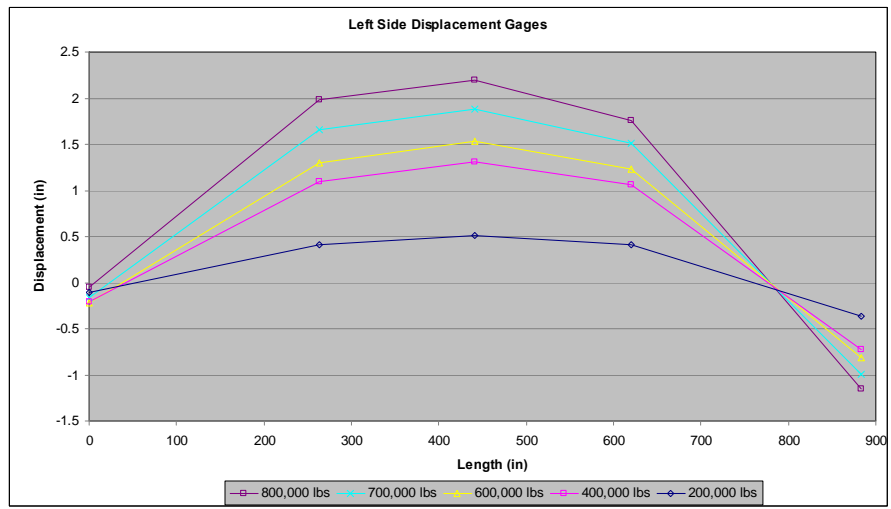

Figure 19. Vertical Displacement Measurements 
On the basis of the posttest analysis of the displacement transducer data, the values shown in this figure have been adjusted to remove effects associated with longitudinal motion of the carbody at the string potentiometer attachment points. These data are undergoing further analysis and may require additional adjustment to account for lateral displacement effects.

\section{Permanent Deformation}

Before the test, a dent was observed in one of the side sills. The damage was to the lower part of the sill, shown in Figure 20. At the maximum static load of 800,000 lb, the dent in the side sill was observed to be visibly larger. After the load was reduced, the dent was observed in the side sill in greater detail. There was no other side sill damage observed as a result of the $800,000-\mathrm{lb}$ test. Figure 21 shows a posttest photos of the side sill damage taken from the side. Figure 22 shows the same side sill viewed from underneath the car. In all photos, the dashed line has been added for clarification.

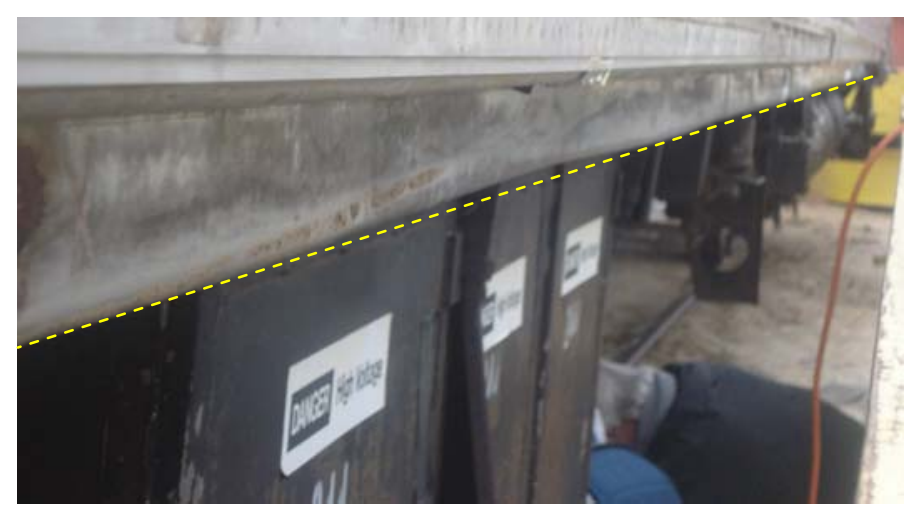

Figure 20 - Pretest Photo of Side Sill Damage

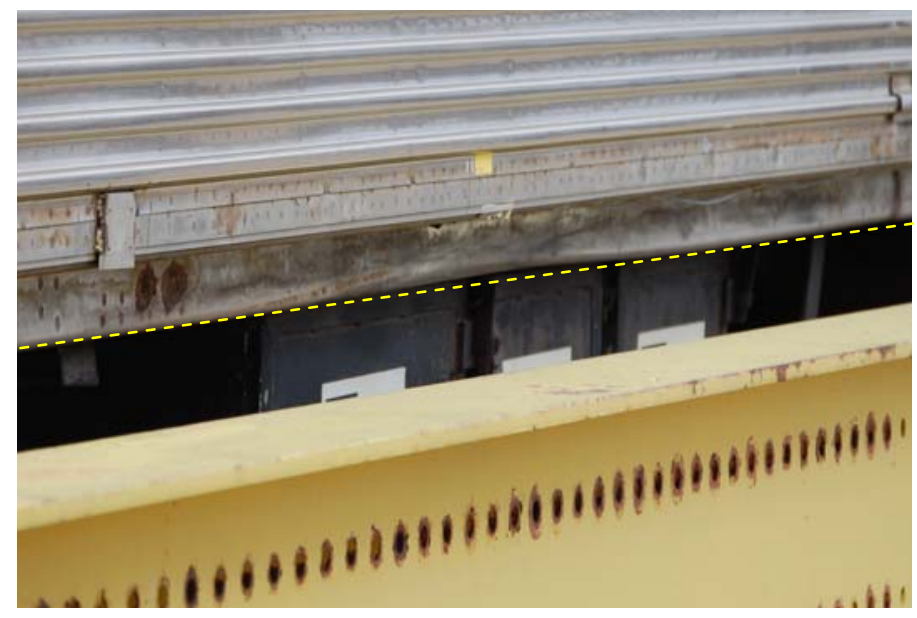

Figure 21 - Posttest Photo of Side Sill Damage

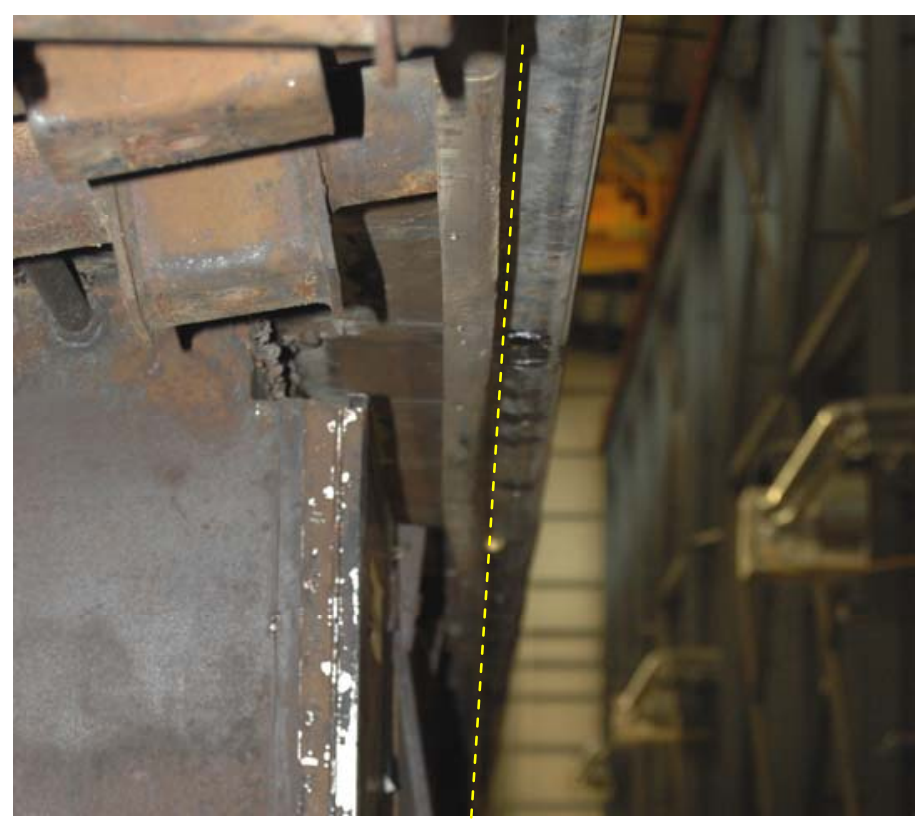

Figure 22 - Posttest Photo of Side Sill Damage from Below

\section{Strain Gage Measurements}

As discussed in an earlier section, strain gages were placed on the major longitudinal members making up the carbody. On the basis of the preliminary examination of the maximum strains recorded on the day of the test, it does not appear that any strains indicating material yield were recorded. Although gages were placed at locations likely to exhibit plastic deformation, it would not be practical to instrument the entire carbody for strains. Therefore, it is possible that localized plastic strains may have occurred within the structure outside of the vicinity of strain gages. Additionally, a more thorough examination of the strain data is ongoing.

\section{Test Outcome}

On the basis of the observations made during the test and a preliminary analysis of the test data, the car appears to have sustained permanent deformation to an area of the side sill where damage was known to exist. This test was run to evaluate the fitness of this car for additional testing and demonstrate a stable mode of deformation under 800,000 lb of applied load. This car will be used in the next two tests of occupant volume integrity as an example of an 800,000-lb compliant car subject to loading along the collision load path.

\section{SUMMARY}

An 800,000-lb compressive strength test was performed on Budd Pioneer Car 244 on January 20, 2010. This test was designed to demonstrate the suitability of this particular test vehicle to future occupant volume tests. Before this test, the 
vehicle was used for dynamic crash testing, including CEM testing. Repairs to the vehicle included removal of CEM components, replacement of trigger shear bolts and shear rivets, and the addition of interference blocks on the sliding sill to assist in load sharing.

Pretest FE predictions indicated a high likelihood of passing this nondestructive test. These predictions estimated the carbody longitudinal shortening of approximately 1.6 in at a load of $800,000 \mathrm{lb}$. Additionally, the carbody was expected to lift at its centerline by approximately $2 \mathrm{in}$.

The global behavior of the carbody was as expected from the pretest predictions based on the preliminary test results analyzed. The carbody was observed to visibly deflect upward at its center and deflect downward at its ends. Preliminary force-displacement behavior indicates close to linear behavior. Preliminary review of strain gage data does not indicate plastic deformation at any recorded locations. However, a pre-existing side sill dent expanded during the conduct of this test. This test article is planned to be utilized in further tests based on the preliminary outcomes of this test.

\section{FUTURE PLANS}

Analysis of the data collected during this test, including video analysis, is ongoing. It is anticipated data may require adjustment to compensate for unanticipated deflection behavior that was recorded in the test. The pretest FE model may require revision to more closely model the actual conditions of the test, on the basis of further analysis of the test data.

As discussed in Reference 11, this program of testing was designed to evaluate the occupant volume integrity of equipment with a nonconventional collision load path. This $800,000 \mathrm{lb}$ test was the first test to be performed, seeking to verify that the test article was suitable for further testing. This vehicle is being used in a further series of tests based on its performance in this test.

The next two tests in this series are designed to evaluate the occupant volume integrity in a manner more closely related to the way collision loads act upon the structure. This will require applying loads to the energy absorber support structure on the occupant volume.

The first energy absorber support test is designed to evaluate the elastic strength of the occupant volume. The car would be loaded until such a time that permanent deformation appears to be imminent. This maximum load without permanent deformation is the elastic load limit for the occupant volume.

In the second test at the energy absorber support structure, the load would be increased until the carbody has crippled. This test would be the most difficult of the three tests to implement, as the load magnitudes are expected to be quite high. Additionally, the carbody structure may cripple in an unexpected way during this test, requiring additional safety measures. As this test requires loading the occupant volume in a nonconventional location, additional instrumentation will be placed on the structure to capture the crippling behavior. This instrumentation will likely include additional load cells and string potentiometers measuring the longitudinal behavior of the car. Additionally, vertical load cells may be used to measure the vertical reaction forces at the carbody support locations. The next two tests are being developed presently.

\section{ACKNOWLEDGEMENTS}

This work was performed as part of the Equipment Safety Research Program sponsored by the Office of Research and Development of FRA. The Program Manager for this work is Eloy Martinez. The authors wish to thank Luis Maal, (FRA), Bob Fries (Association of American Railroads), and Tom Roderick (Association of American Railroads) at Transportation Technology Center for their assistance in planning and implementing this test. The authors also wish to express their gratitude to Dr. Benjamin Perlman at the Volpe Center for his helpful insights into analyzing the test data. The Budd Pioneer car used in this test was donated by the Southeastern Pennsylvania Transportation Authority.

\section{REFERENCES}

1. Carolan, M., Muhlanger, M., "Strategy for Alternative Occupant Volume Testing" American Society of Mechanical Engineers, Paper No. RTDF2009-18025, October 2009.

2. Mayville, R., Rancatore, R., Stringfellow, R., and Amar, G., "Repair of Budd Pioneer Coach Car Crush Zones." U.S. Department of Transportation, DOT/FRA/ORD-07/18, May 2007.

3. U.S. Department of Transportation, Federal Railroad Administration, "49 CFR Part 216 et al., Passenger Equipment Safety Standards; Final Rule,” Federal Register, May 12, 1999.

4. American Passenger Transportation Association, “APTA SSC\&S-034-99, Rev. 2. Standard for the Design and Construction of Passenger Railroad Rolling Stock,” June 15, 2006.

5. Tyrell, D., Severson, K., Perlman, A.B., "Single Passenger Rail Car Impact Test Volume I: Overview and Selected Results," US Department of Transportation, DOT/FRA/ORD00/02.1, March 2000.

6. Martinez, E., Tyrell, D., Zolock, J., "Rail-Car Impact Tests with Steel Coil: Car Crush," American Society of Mechanical Engineers, Paper No. JRC2003-1656, April 2003.

7. Jacobsen, K., Tyrell, D., Perlman, A.B. , "Impact Test of a Crash-Energy Management Passenger Rail Car," American Society of Mechanical Engineers, Paper No. RTD2004-66045, April 2004. 
8. Jacobsen, K., Tyrell, D., Perlman, A.B., "Impact Tests of Crash Energy Management Passenger Rail Cars: Analysis and Structural Measurements," American Society of Mechanical Engineers, Paper No. IMECE2004-61252, November 2004.

9. Tyrell, D., Jacobsen, K., Martinez, E., “A Train-to-Train Impact Test of Crash Energy Management Passenger Rail Equipment: Structural Results," American Society of Mechanical Engineers, Paper No. IMECE2006-13597, November 2006.

10. Alcoa Fastening Systems. "Huck BOM ${ }^{\circledR}$ - The Highest Strength Blind Bolt in the World." World Wide Web: http://www.alcoa.com/fastening_systems/commercial/catalog/pdf/huck/en/AF2

01_Bom_Brochure.pdf. Accessed January 11, 2010.

11. Abaqus/CAE Version 6.9-1, 2009, Simulia, Inc.

Providence, RI, USA 